\title{
The Role of Social Networks in Small Island Communities: Lessons from the 2017 Atlantic Hurricane Season
}

\author{
Briony Gray \\ University of Southampton \\ Bjg1g11@soton.ac.uk
}

\author{
Mark Weal \\ University of Southampton \\ mjw@ecs.soton.ac.uk
}

\author{
David Martin \\ University of Southampton \\ D.J.Martin@soton.ac.uk
}

\begin{abstract}
The 2017 Atlantic hurricane season was abnormally destructive. For small island developing states (SIDS) a range of underlying issues such as climate change and infrastructure failures also heightened risk. With the increased use of social media and other digital technologies, communities within SIDS are relying on new methods of information dissemination during crises. This paper analyses the ways in which social media and other digital technologies are used in the Caribbean for hurricane resilience and preparedness, using the case study of Antigua and Barbuda that were particularly damaged during the 2017 season. The study scopes the place of such technologies at present through the use of qualitative interviews from a range of governmental departments, organisations, humanitarian aid charities, ex-politicians, business owners and members of the public. It concludes by deriving three main lessons for SIDS for the better management of future hurricane seasons.
\end{abstract}

\section{Introduction}

Globally, natural hazards are becoming more frequent and severe than previously thought due to underlying issues such as climate change [1]. Hurricane seasons in particular have been influenced by unpredictable variations in the El Niño phenomenon, leading to record-breaking periods and unpredictable intensification of storm systems [2]. The 2017 Atlantic hurricane season, as such an example, was abnormally destructive; especially for small island developing states (SIDS) and by extension small island communities (SICs) in the Caribbean [3]. Its severity was characterised by a series of ten hurricanes, six of which were categorised as major. The most notable of these were Harvey, Irma and Maria, which according to the UNISDR (2018) caused total damages in excess of US $\$ 477.5$ billion, with more than 400 fatalities, and affecting thousands of individuals across numerous countries.

In recent years, there has been an increased uptake of digital technologies and social media for the creation and dissemination of information during disasters [4]. Social media in particular have become more extensively used due to a range of benefits. They are free, easy to use, and can be utilized in real-time [5]. The use of social media during disasters is extensive and has been well-documented (see for example Reuter \& Kaufhold's history of signifcant disaster case studies, 2017). Many prominent case studies use social media data as a lens for analysis, which, while valuable in creating an understanding of a crisis event, often does not fully scope the role and place that the resource holds within communities themselves [7].

The incorporation of social media as tools for disaster management and crisis communications has been a fairly new trend for many SIDS [8]. This is significant for such populations as they have compressed spatial scales, meaning that local level is often no different from national level [9]. Consequently, SIDS tend to rely on local expertise and knowledge as there is limited option to scale up disaster response in the short-term [10]. New methods of knowledge sharing that aid communications - not only within SICs, but also to neighboring SIDS - are therefore increasingly important for disaster management and response in isolated geographical regions of the world [11]. This is especially important for countries with low GDP, fewer or infrequent international transport links, limited resources and small scale technological infrastructures [9], [10].

Given the reoccurring nature of the Atlantic hurricane season there is an urgent need to learn from past and present methods of disaster management and 
response [3]. Specifically in SIDS, the role of social media during crises needs to be defined and understood in the hurricane context [3], [10], [12]. Additionally, it should be explored in the context of long-term resilience and preparedness efforts as social media are more extensively being used by governments, humanitarian aid organisations, public health authorities, economic stakeholders, military deployment initiatives, and by the general public [8]. This is paramount to ensure that online services and networks can be utilized to their potential, without increasing risk or undermining existing methods of disaster management and response [13].

This paper seeks to explore the role of social media and networks within SIDS during the 2017 Atlantic hurricane season. Primarily it contributes understanding to the use of social media by organisations and the government. It does this by drawing on the experiences, information and commentary from a range of individuals involved in such organisations, as well as from the wider public who experienced the 2017 season first-hand. Data is collected from the case study SIDS of Antigua and Barbuda, as these islands suffered some of the highest levels of damage during the 2017 season which is still part of an ongoing recovery effort. The study draws data from the Recovery of Caribbean Community from Hurricanes project (RECCOH) funded by the HEIF Research Collaboration Stimulus Fund (2017). The project collects mixed data examining the ways in which disaster management and recovery can be improved on a long-term scale in future hurricane seasons. From this, the role of social media in SIDS is scoped and a way forward is outlined.

\section{Contextualizing Social Media in SIDS during the Hurricane Season}

During the past decade, a plethora of studies have emerged which evaluate the use of social media during disasters. These tend to be case study orientated, and assess many different forms of social media, features and functions [14]. Through such studies a range of positive and negative aspects have been found, groups of users and networks have been defined, and interdisciplinary perspectives have been formed [6]. Within this discourse the study of prominent hurricanes have similarly contributed understanding to the field of disaster management, highlighting disaster and hazardspecific aspects of social media. Notable examples of this include the discovery that social media information carries less credibility than offline media during hurricane Katrina [15], refining content classification algorithms in each of the disaster lifecycle phases during hurricane Isaac [16], and the way in which emergency responders utilise social media channels during hurricane Sandy[17].

In SIDS, social media is taking on a new role during disasters; especially in hurricane preparedness and recovery [13]. Case studies in SIDS around the world have reported a number of additional issues in social media use when compared with more developed countries [3]. Firstly, the management of climate risks is a primary concern for island nations. The proactiveness of local governments in such cases has been found to play an integral role in managing hurricane risk [18]. The call for governments, institutions, and local communities to invest in anticipatory planning that utilizes social media has been proposed in the Cayman Isles [18]. Similarly, in Trinidad and Tobago, it has been suggested that more integrated use of social media policy is needed to ensure better coordinated mitigation, adaptation and communication [19].

A secondary challenge for SIDS is developing long-term technological infrastructure to improve information dissemination: not only during hurricanes themselves, but throughout the rest of the year also [11]. Findings in generalized disaster social media and communications emphasize that an individual's use of technologies for disaster purposes tail off sharply after a disaster has occurred [20] [21][4]. However, social media affordances such as access to networks and information visibility has been shown to improve disaster preparedness and resilience [22] - core aspects for SIDS prone to annual hurricanes [23][24]. A study in Mauritius found that understanding how preparedness information was exchanged throughout periods of calm was valuable in reducing vulnerability [25]. However, there is little published material that assess the role of social media by SIDS after the hurricane season has ended.

\section{Motivations: the Case of Antigua and Barbuda}

Antigua and Barbuda are two islands that form one independent country. They are situated in the Atlantic Ocean where it meets the Caribbean Sea in the Leeward Islands, which are a part of the Lesser Antilles. This case is valuable to assess as a number of sociological, political and geographical factors dictate how well the country manages the annual hurricane season. Firstly, it has a population of around 81,000 permanent citizens. This means that response volunteers are often required to be sent through international aid [8]. Secondly, it has low annual GDP, meaning that expensive and high maintenance technologies and systems are often unavailable for 
disaster management, response and relief [3]. The geographical location of the islands mean that awareness of the annual hurricane season is high, and communication between other SIDS during this period is essential [3]. However, isolation means that hazards - such as rough seas - can essentially cut-off the islands from resources, making issues such as evacuation or resource allocation difficult. Finally, the islands are subject to political tensions, making disaster management a contested aspect of island life.

There is little published material that defines the role of social media during hurricanes specifically in SIDS. This is especially the case in the Caribbean where research tends to focus on environmental perspectives and tourism. For SIDS increasingly using social media there is a need to evaluate the current place it holds within SICs, and to evaluate in what ways policy, services and disaster management protocols should be designed to uphold its use in beneficial ways. Not only do these lessons hold value to the country of Antigua and Barbuda, who are still in recovery mode, they may additionally act as a blueprint for similar SIDS across the Caribbean. This makes the case extremely interesting, as there has been little consolidation of lessons from the hurricane season between the organisations managing the disaster. Therefore, the motivations of this study are to ascertain the role of social media in the context of the hurricane season, and to report findings relevant to other SIDS in coming hurricane seasons with the mind to support further use of social media for disaster resilience and preparedness efforts. The method for this is outlined in the following section.

\section{Method}

The study described in this paper is part of a larger interdisciplinary research project titled "The Recovery of Caribbean Communities from Hurricanes" (RECCOH), based at the University of Southampton. In this paper, data collected from qualitative interviews with individuals who experienced the 2017 Atlantic hurricane season are presented which scope the role that social media had during this period.

\subsection{Participants and Procedure}

Recruitment for qualitative interviews was performed through purposive sampling. This began with the Antiguan High Commission, with whom the project was liaising with. Relevant individuals within the Commission were approached and asked to provide a consultation, which was then used to determine communities and organisations of interest. Using expert local knowledge the study conducted a shortlist of individuals. Inclusion criteria dictated suitable interviewees must be over 18, were residents of Antigua and Barbuda, had experienced the 2017 Atlantic hurricane season, and had used social media during at least one stage of the disaster lifecycle. Exclusion criteria for participants was being under the age of 18, not being present during the season at all, or subject to any mental or physical illness that may cause anomalous results. According to the World Bank Group (2018), 73\% of the population of the country has access to the internet, with some $63 \%$ of citizens owning a mobile device. This provided an appropriately large pool from which to source interviewees.

Snowball sampling was employed on the shortlist. Interviewees were invited to participant in a qualitative interview, lasting between 30-60 minutes, by either word of mouth or email (if this information was publicly available). This ensured that high quality data was collected from the most relevant individuals who originated from a variety of backgrounds: for example governmental ministers, humanitarian aid workers, relief volunteers and members of the public. Sampling increased the likelihood that individuals were a part of networks of interest who engaged with disaster preparedness and response. Members of the public were included to ensure that a commentary of the users of social media could be recorded to reflect how organisations and government were using digital technologies during the disaster. Finally, sampling allowed control over the data saturation point, and for interviewees to recommend other individuals who may be important for the project. It is important to note however that this data is not treated as a representative sample of the Antiguan and Barbadian total population.

\section{Results}

More than 90 participants were interviewed regarding the 2017 Atlantic hurricane season, from a range of different backgrounds. A summary of these can be found in table 1 . 
Table 1. An overview of the organisations and individuals interviewed about the 2017 Atlantic hurricane season in Antigua and Barbuda.

\begin{tabular}{|c|c|c|}
\hline Organisation & Brief Overview & No. \\
\hline $\begin{array}{l}\text { The Antigua and } \\
\text { Barbuda Meteorological } \\
\text { Centre }\end{array}$ & The National Meteorological Centre for the Country. & 1 \\
\hline $\begin{array}{lr}\text { The } & \text { National Solid } \\
\text { Waste } & \text { Management } \\
\text { Authority }\end{array}$ & $\begin{array}{l}\text { A service to provide residents with an integrated, cost effective solid waste management system that } \\
\text { follows the guidelines of environmentally sound principles. Responsible for hurricane debris clean-up } \\
\text { efforts and organisational coordination for environmental issues. }\end{array}$ & 5 \\
\hline $\begin{array}{l}\text { The University of the } \\
\text { West Indies }\end{array}$ & $\begin{array}{l}\text { The main university of the Caribbean islands with four landed campuses, and many open campuses. } \\
\text { Responsible for informing regions about disaster risk reduction. }\end{array}$ & 8 \\
\hline $\begin{array}{l}\text { Ministry of Agriculture, } \\
\text { Lands, Fisheries and } \\
\text { Barbuda Affairs }\end{array}$ & $\begin{array}{l}\text { A service for the application of modern and emerging practices designed to strengthen food security } \\
\text { initiatives, efficient land use management and sustainable development of natural resources. Responsible } \\
\text { for a series of hurricane-related response initiatives. }\end{array}$ & 9 \\
\hline $\begin{array}{l}\text { The Ministry of } \\
\text { Education }\end{array}$ & $\begin{array}{l}\text { A service to offer the highest quality education possible to children and young people, from pre-school to } \\
\text { post graduate level. Responsible for the integration of hurricane evacuees into Antiguan social systems. }\end{array}$ & 4 \\
\hline ZDK Radio Station & $\begin{array}{l}\text { A local radio station available to the residents of Antigua and Barbuda. Responsible for hurricane } \\
\text { information dissemination. }\end{array}$ & 1 \\
\hline ABS Radio Station & $\begin{array}{l}\text { A local radio station available to the residents of Antigua and Barbuda. Responsible for hurricane } \\
\text { information dissemination. }\end{array}$ & 2 \\
\hline $\begin{array}{l}\text { The Observer Radio } \\
\text { Station }\end{array}$ & $\begin{array}{l}\text { A local radio station available to the residents of Antigua and Barbuda. Responsible for hurricane } \\
\text { information dissemination. }\end{array}$ & 2 \\
\hline The Barbuda Council & $\begin{array}{l}\text { The Council runs the internal affairs of Barbuda. Members are elected by the registered voters of Barbuda, } \\
\text { with the Parliamentary Representative (MP) and the Senator, who is nominated by the Council, as ex- } \\
\text { officio members. The council administers and regulates agriculture, forestry, public health, public utilities } \\
\text { and roads as exclusive powers, and raises and collects revenue to meet expenses incurred in the } \\
\text { performance of its functions. }\end{array}$ & 9 \\
\hline Red Cross Antigua & $\begin{array}{l}\text { The Antiguan branch of the Red Cross, which provides services in the areas of health, welfare, disaster } \\
\text { relief, first aid and youth development. }\end{array}$ & 1 \\
\hline The WAITT Institute & $\begin{array}{l}\text { The Institute partners with governments committed to developing and implementing comprehensive, } \\
\text { science- based, community-driven solutions for sustainable ocean management. }\end{array}$ & 5 \\
\hline $\begin{array}{l}\text { The Community } \\
\text { Development Project }\end{array}$ & $\begin{array}{l}\text { A branch of the Ministry of Social Transformation of the government dedicated to supporting individuals } \\
\text { and communities who are vulnerable in society. }\end{array}$ & 4 \\
\hline $\begin{array}{l}\text { The Antigua Lions } \\
\text { Organisation }\end{array}$ & A non-profit service organization helping people in Antigua \& Barbuda and the surrounding communities. & 1 \\
\hline $\begin{array}{l}\text { Antigua Public Utilities } \\
\text { Authority }\end{array}$ & $\begin{array}{l}\text { A tripartite government statutory agency to ensure that consumers receive the best possible value in } \\
\text { Telecommunications (including mobile \& internet), Electricity and Water services. }\end{array}$ & 3 \\
\hline $\begin{array}{l}\text { Digicel } \\
\text { Telecommunications }\end{array}$ & One of the major telephone and internet communication providers in Antigua and Barbuda. & 5 \\
\hline $\begin{array}{l}\text { Antigua and Barbuda } \\
\text { Individual Politicians }\end{array}$ & A collection of individuals from various governmental departments. & 6 \\
\hline $\begin{array}{l}\text { Antigua and Barbuda } \\
\text { ex-politicians }\end{array}$ & A collection of individuals who were once in office in the country, including the ex-prime minister. & 3 \\
\hline The High Commission & The High Commission for Antigua and Barbuda affairs. & 4 \\
\hline Local Business Owners & $\begin{array}{l}\text { A range of individuals that own business across Antigua and Barbuda, ranging from Taxi drivers to shop } \\
\text { owners. }\end{array}$ & 12 \\
\hline $\begin{array}{l}\text { Members of the } \\
\text { Antiguan and Barbudan } \\
\text { Public }\end{array}$ & $\begin{array}{l}\text { A collective of individuals who experienced the } 2017 \text { Atlantic hurricane season in Antigua and Barbuda. } \\
\text { These were able to inform the project of how they utilized social media, what disaster management and } \\
\text { response involved from a civilian perspective, and comment on the nature of social media use of } \\
\text { organisations and the government. }\end{array}$ & 20 \\
\hline
\end{tabular}




\section{The Role of Social Media in SIDS during the Atlantic Hurricane Season}

\begin{abstract}
Members of the public, governmental departments, organisations and charities are increasingly using social media in SIDS. As the islands of Antigua and Barbuda have invested in more hightech telecommunications in the past five years, the number of individuals with smart phones is increasing. Consequently, many more people can access and use social media via smartphones supported by local mobile operators such as Digicel and Flow. Facebook is primarily the most used platform due to its affordances, which feature connectivity, visibility, and created stressors which may influence information spread in networks [26]. It allows for the creation of groups and pages for the sharing of specific, themed information (for example hurricanes), which individuals may interact with and share to others. The structure of the Facebook "timeline" is similar to the structure of communities in real life. By this, we mean that the timeline feature highlights news from people we have the most interactions with, and presents it to us first thus making us the most aware of these individuals. This is valuable for the mitigation of the Atlantic hurricane season for two main reasons: using social media as a tool for community disaster resilience and preparedness, and as a means of crisis communications itself.
\end{abstract}

\subsection{Social Media for Resilience and Preparedness}

The general resilience and preparedness of Antigua and Barbuda is high due to the reoccurring nature of the hurricane season. A majority of the country's resilience and preparedness efforts originate from the pre-disaster phase. During the lead up to the hurricane season, a range of warning media is broadcast across the islands, predominantly on TV and radio channels. These explain to citizens what they should do to reduce their risk before any hazards transpire. In the previous two years, governmental ministries and some organisations - for example the MET office - have been expanding warnings onto social media in the form of Facebook and Twitter also. While this represents good practice for such organisations in a country that is rapidly utilizing better telecommunications and infrastructure, there remains many areas for improvement. However, Facebook presence may in fact indicate social pressure to access the site regularly as a negative stressor [26]. For example, many smaller organisations who had reduced response to the hurricanes admitted to having a Facebook page, but not using this regularly for information dissemination. They acknowledged that they believed extending warnings onto social media was a valuable thing for the public, and so followed the trend - with Facebook being one of the most popular due to its affordances. There were general barriers to Facebook use that many individuals shared (for example mobile networks collapsing), as well as specific barriers (for example individuals seeking information from pages, groups or accounts that disseminate unverified or outdated information which was generally only a problem for official governmental accounts). While resilience and preparedness in the pre-disaster stage was high, interviewees explained that during and after the hurricanes - particularly that of Irma - the use of social media for crisis communications became problematic.

\subsection{Social Media for Crisis Communications}

In September 2017, Barbuda was hit by hurricane Irma and sustained substantial damages. One of the most harmful was the outage of mobile networks that essentially isolated the entire island for two days, before satellite phones managed to get through. For a following week, contact between the islands was severely limited, which complicated the evacuation of Barbuda over to Antigua - a first in the country's history. During this period of crisis, individuals and organisations alike attempted to communicate between the two islands using any methods available to them. Interviewees explained that WhatsApp was the most reliable service that was functioning, aside from radio and satellite phones, which were severely limited in number. WhatsApp is a service that has end-to-end encryption, meaning that communications weren't open or publically available. Consequently, the service was used to contact individuals directly (requiring unique mobile phone numbers): a method that organisations, governmental ministries and humanitarian aid charities were also relying on due to collapses in internal and inter-organisational methods of communication. Ultimately, this excluded individuals who did not have direct contacts on the service, and so increased their risk based on their personal real-life relationships. The reliance of organisations on a range of back-up technology highlights the continued importance of conceptual HCI theories where emergency management teams are supported by technology but not driven by it [22].

Despite the use of social media for resilience and preparedness efforts, Antigua and Barbuda commonly face structural issues that can undermine the effectiveness of such methods. Many individuals using 
social media for crisis communications throughout the 2017 Atlantic hurricane season reported severely intermittent services, that, in some cases, caused significant worry and panic. Furthermore, the complete lack of communication after the mobile network collapse heightened national anxieties regarding the fate of Barbudan citizens, as well as rendering emergency SMS services unavailable. Following this, underlying geographical, sociological and political factors later shaped the way in which social media was used. The geography of Barbuda is extremely flat, meaning that mobile telephone masts and other physical infrastructure are unprotected against hurricanes and so sustain immediate damage. The isolated nature of both islands means that when the seas are rough, it is difficult for ships to safely travel and dock, and for planes to traverse. Therefore, communications and coordination must face an additional element of detachment while still being critical in disaster management efforts. Instead, the national emergency communications plan outlines in such situations emergency SMS use is disregarded, and satellite phones, radio (and in this particular season WhatsApp too) are to be used.

Finally, the politics between the islands of Antigua and Barbuda are complex. This has made communication between the Antiguan government and the Barbudan council multi-faceted, with many individuals believing that a more unified government could have better handled the damages sustained in Barbuda. This ultimately reflects an underlying sociotechnical infrastructure to disaster response in the country, as opposed to a conceptual one, where humandriven resilience compensates for the break-down in technologies [27]. Furthermore, it illustrates the need for further research of social media to take into consideration non-technical factors and theory, which are argued by a wealth of HCI disaster literature to have strong influences on socio-behavioural scales [4].

\section{The Three Key Areas for Building Hurricane Resilience and Preparedness in SIDS}

There are a number of possible ways that social media use can be improved upon during the Atlantic hurricane season. In the case of Antigua and Barbuda the interviews have highlighted four key areas. Although resilience and preparedness before the hurricane season is high, many governmental ministries and humanitarian aid charities postulate that education is still of the highest importance in order to further reduce risk. The reliability of communications is also a significant area for improvement which needs to take many forms: (i.) communication between the islands of Antigua and Barbuda themselves, (ii.) internal communication between governmental departments, (iii.) inter-organisational communication between the government and other organisations, (iv.) charities involved in disaster management, and (v.) generalized communication from the government (and relevant organisations) to the public. Interviews with organisations and governmental ministries revealed that most had to adapt to unexpected situations during the hurricane season to reduce risk posed to the public. Although this was valuable during all phases of crises, almost no record of the lessons that these teams learnt managing the disaster have actually been logged. Finally, the issue of short-term mitigation efforts were highlighted as a barrier to long-term solutions. Humanitarian aid charities in particular theorized that an over-reliance short-term planning and methods, while valuable in immediate effect, detracts funding and planning away from more substantial long-term methods of reducing risk. Instead, the importance should be placed on these to relieve future hurricane season for years to come; especially considering worsening factors such as climate change.

\subsection{Improving Hurricane Education Resources}

"To teach them, we must first reach them" The Ministry of Education for Antigua and Barbuda.

Unanimously, the organisations and governmental ministries responsible for the creation and dissemination of information during disasters highlighted education as a priority. With the increased availability of smart phones, people's social media habits are changing. Interviewees noted that now, especially the younger generations, are relying on such devices for educational needs (for example bringing them to school to take pictures of work instead of writing), as well as more common social needs (for example social networking). Consequently, there is value in expanding hurricane warning and preparedness information to be hosted online publicly.

Online education resources should be tailored to the population's needs in order to be the most effective at reducing risk. This means having a series of resources designed to reach each age bracket, where the language, style and message suits the needs of the intended audience. Additionally, sources should use a range of different visualizations to suit different learning needs. This is valuable in populations where preparedness and awareness of the hurricane season is already high, thus a change in medium and style of the message can act as a psychological "shock" [28], [29], 
and result in individuals maintaining high awareness and preparedness [30], [31].

Any online education resources created should be uniformly hosted across all official services and sites. They should also be uniform in their message (not medium), despite differences in style. Many studies in disaster literature indicate that contrasting or conflicting information originating from different sources can negatively impact the public, especially if they are using it to make safety-critical decisions [32][34]. By hosting the same educational resources in this way, individuals may face fewer decisions to make during times of crisis, as each of the official sites that manage the hurricane season support the same information. Reducing decision-making during disasters is theorized to lessen risk [35].

\subsection{Improving Crisis Communications}

"No one really knew the full picture about what was happening. Departments and other external organisations were told that we were the ones supplying them with national information updates, which they themselves would then put out to the public - but we were being told a different thing by the people in charge." National Office for Disasters (NODs) for Antigua and Barbuda.

During periods of crisis, communication between official organisations (i.e. governmental departments, organisations and humanitarian charities, and established volunteer groups) is of paramount importance. During the 2017 Atlantic hurricane season many of these bodies reported that there was a lack of internal protocols for communications. Instead, organisations were sharing any of their information with NODs, and were informed that real-time updates would be issued by this department. NODs however were understaffed, had little communications in place with wider organisations, and were not able to access or collect large amounts of data from across the islands due to the power outages and collapse of mobile networks. In light of these issues, establishing a communications protocol interdepartmentally, as well as inter-organizationally is valuable to future seasons.

"We were having to send out individuals across the island to stand with walkie-talkies and tell us about what was going on” - NODs employee.

Communication between the islands was a significant issue during the 2017 season. In response to this, mobile network providers have begun to rebuild the damaged structures on Barbuda using methods to reinforce against hurricanes. Similarly, the minister for Agriculture, Fisheries and Barbudan Affairs outlined plans to lay an underwater fiber optic cable between the islands to avoid the complete communications isolation of the previous season. In addition to these, the use of satellite phones or VHF radios would be valuable for the islands given their geography, and their subjectivity to hazards which can isolate whole communities. Despite these plans, the notion of human-driven resilience remains of paramount importance to SIDs where technological infrastructures may potentially take decades to grow, and to become more consistently reliable during disasters [27].

Communications between official bodies and the public followed three main methods after the mobile networks collapsed. Firstly, local radio stations broadcast information they received from official bodies on a 24 hour reel. Secondly, many of the larger organisations employ hotlines that individuals may call for spoken updates, manned by people rather than automation. Thirdly, teams from certain departments, such as the Community Outreach team, physically made house calls around communities to check on people's welfare. Collaboratively these provided information to the public; however they may still be improved by incorporating best practices from other emergency methods of communication. Lessons from Hurricane Katrina indicated that rapid dissemination of information within the government, automatic triaging, organisations supporting different types of communication, and the ability to phase key risk messages are all ways forward [36], [37].

"We ended up taking over operations and allocating resources in areas that weren't our jurisdiction simply because no others were doing it. We learnt a lot of lessons in the moment, and had to adapt to every change the hurricane [Irma] threw at us" - The Community Outreach Team, the Department of Social Transformation for Antigua and Barbuda.

Even in countries with high preparedness, hurricanes can overwhelm communities and services. To address this, disaster response must use their experience, training and planning to mitigate the negative effects of future events. Sharing experiences though "lessons learned" mechanisms has been proven valuable in many disaster case studies, particularly in cases featuring re-occurring disasters such as the hurricane season [16], [38], [39]. While such knowledge filters through communities in Antigua and Barbuda on a word-of-mouth basis, very few are written down or shared purposefully with bodies managing crises. During the 2017 Atlantic hurricane season a number of unexpected events occurred that required quick thought and changing plans for emergency management.

One such example was the Department for Social Transformation, who took on resource allocation for citizens evacuated from Barbuda. During 
this unexpected evacuation the team learnt many valuable lessons as the islands had never before experienced an island-wide evacuation before. Similarly, the team learnt many lessons from other tasks and teams that they had never before been trained in, as well as new utilization of social media that mainly took for form of WhatsApp messaging. These lessons are of paramount importance for the preparedness of the country in future hurricane seasons - however none of these have been discussed within government, shared between departments, or even written down in a sharable format.

Naturally, then, a lessons learnt approach should be employed by the government and organisations. This should initially take the form of national inter-organisational and departmental discussions, from which key lessons may be synthesized from the large amounts of qualitative data. Further collaboration is needed between such bodies to further identify and refine the key lessons, and then to draw this up into a document or manual to be used as a support for hurricane preparedness in future seasons. Additionally, a lessons learnt enquiry within departments and organisations themselves may prove valuable in shedding light on the performance of smaller scale networks. This has proven particularly effective for more insulated services such as individual trauma wards, singular volunteer groups, and small teams working within larger governmental departments [40]. Finally, theory on affordances of particular social media need to be considered in greater detail, principally in the context of SIDs, which feature unique social demographics and infrastructures [41].

\section{Conclusions}

Managing the Atlantic hurricane season is a challenge for many SIDS. A number of geographical, sociological and political underlying factors shape this response, as well as environmental drivers such as climate change. The use of social media and similar digital technologies has been shown to have a place in the sharing of resilience and preparedness information in Antigua and Barbuda. Similarly, its use for crisis communications has been valuable until the point of network and infrastructure failures after the landfall of hurricane Irma. This highlights the importance of HCI theory stipulating that emergency management teams must be supported by technology, but not driven by it [22]. With the islands improving their technological infrastructure social media is increasingly taking on a role within communities, both in times of calm as well as during crises. Ultimately, understanding how this role is changing can illustrate the ways in which it may be better utilised within a hurricane-specific context.

In light of these issues, the use of social media can be improved in three main areas. (i.) The creation of a range of targeted online education tools and visualizations, hosted online by a range of bodies managing the hurricane season, may maintain high levels of resilience and preparedness in communities. (ii.) The adoption and improvement of communication protocols between within government and organisations, between managing bodies, and from bodies to the public may improve situational awareness throughout all phases of the disasters. Furthermore, investing in different mediums of communication may additionally improve disaster response and recovery. (iii.) The consolidation of lessons learnt from a range of individuals and bodies during the 2017 Atlantic hurricane season may hold significant value: not only in improving hurricane response, but also in further understanding the role that social media holds within communities on SIDS.

To conclude, findings from the 2017 Atlantic hurricane season are important for the management of future seasons. Record-breaking winds, storm strength, and rapid intensification of hurricanes made it a particularly difficult and complex season to manage. Now, there is a question as to whether the 2018 season, and following seasons, may also follow this new and destructive trend. With so many SIDS exposed to sea level rise, subjected to island politics and shaped by institutional approaches to adaption the need to place hurricane resilience highly should be a concern for all at risk islands. In addition to this, the paper acknowledges that HCI theory must be applied to such cases and across a range of social media platforms. Analytical focus in future research must consider affordances, the design of user interfaces to tailored populations (especially in SIDs which have a lower percentage of the population with access to the internet and mobile devices), and the perception of crisis communications themselves [41].

\section{References}

[1] M. S. Kappes, M. Papathoma-Köhle, and M. Keiler, "Assessing physical vulnerability for multi-hazards using an indicator-based methodology," Appl. Geogr., vol. 32, no. 2, pp. 577-590, Mar. 2012.

[2] M. Enenkel, S. M. Saenz, D. S. Dookie, L. Braman, N. Obradovich, and Y. Kryvasheyeu, "Social Media Data Analysis and Feedback for Advanced Disaster Risk Management,” Feb. 2018.

[3] J. M. Shultz, J. P. Kossin, J. M. Shepherd, J. M. Ransdell, R. Walshe, I. Kelman, and S. Galea, "Risks, Health Consequences, and Response Challenges for Small-Island-Based Populations: 
Observations From the 2017 Atlantic Hurricane Season,” Disaster Med. Public Health Prep., pp. 113, Apr. 2018.

[4] L. Palen and A. L. Hughes, "Social Media in Disaster Communication,” Springer, Cham, 2018, pp. 497-518.

[5] S. Luna and M. J. Pennock, "Social Media Applications and Emergency Management: A Literature Review and Research Agenda,” Int. J. Disaster Risk Reduct., Jan. 2018.

[6] C. Reuter and M.-A. Kaufhold, "Fifteen years of social media in emergencies: A retrospective review and future directions for crisis Informatics,” $J$. Contingencies Cris. Manag., Sep. 2017.

[7] B. Gray, M. Weal, and D. Martin, "Social media and disasters: a new conceptual framework."

Proceedings of the ISCRAM 2016 Conference, 28Feb-2016.

[8] D. D. P. Thompson, "Disaster logistics in small island developing states: Caribbean perspective," Disaster Prev. Manag. An Int. J., vol. 24, no. 2, pp. 166-184, Apr. 2015.

[9] F. (Sociologist) Krüger, G. Bankoff, T. Cannon, B. Orlowski, and L. Schipper, Cultures and disasters : understanding cultural framings in disaster risk reduction. 2015.

[10] I. Kelman, T. R. Burns, and N. M. des Johansson, "Islander innovation: A research and action agenda on local responses to global issues," J. Mar. Isl. Cult., vol. 4, no. 1, pp. 34-41, Jun. 2015.

[11] J. M. Shultz, M. A. Cohen, S. Hermosilla, Z. Espinel, and A. McLean, "Disaster risk reduction and sustainable development for small island developing states,” Disaster Heal., vol. 3, no. 1, pp. 32-44, Jan. 2016.

[12] B. F. Battistoli, T. King, and E. White, "Voices in the Storm: The Lost Discourse of Climate Change in Hurricanes Harvey and Irma,” Int. J. Cris. Commun., vol. 1, no. 1, pp. 72-78, Jan. 2018.

[13] T. R. Zolnikov, “A Humanitarian Crisis: Lessons Learned From Hurricane Irma.,” Am. J. Public Health, vol. 108, no. 1, pp. 27-28, Jan. 2018.

[14] Anderson, "Supporting Disaster Reconnaissance with Social Media Data : A Design-Oriented Case Study of the 2013 Colorado Floods,” no. May, pp. 632-641, 2014.

[15] H. Purohit, A. Hampton, S. Bhatt, V. L. Shalin, A. P. Sheth, and J. M. Flach, "Identifying Seekers and Suppliers in Social Media Communities to Support Crisis Coordination,” Comput. Support. Coop. Work, pp. 513-545, 2014.

[16] L. Kantha, "Classification of hurricanes: Lessons from Katrina, Ike, Irene, Isaac and Sandy,” Ocean Eng., vol. 70, pp. 124-128, Sep. 2013.

[17] J. White, L. Palen, and K. Anderson, "Digital mobilization in disaster response: the work \& selforganization of on-line pet advocates in response to hurricane sandy," Conf. Comput. Coop. Work Soc. Comput., no. October, pp. 866-876, 2014.

[18] M. Pelling and J. I. Uitto, "Small island developing states: natural disaster vulnerability and global change,” Environ. Hazards, vol. 3, pp. 49-62, 2001.

[19] K. Hassanali, "Challenges in mainstreaming climate change into productive coastal sectors in a Small Island State - The case of Trinidad and Tobago," Ocean Coast. Manag., vol. 142, pp. 136-142, Jun. 2017.

[20] J. Kim and M. Hastak, "Social network analysis: Characteristics of online social networks after a disaster,” Int. J. Inf. Manage., vol. 38, no. 1, pp. 8696, Feb. 2018.

[21] K. McNutt, "Public engagement in the Web 2.0 era: Social collaborative technologies in a public sector context.," Can. Public Adm., vol. 57, no. 1, pp. 4970, 2014.

[22] L. Carver and M. Turoff, "Human-computer interaction: The human and computer as a team in emergency management information systems," Commun. ACM, vol. 50, no. 3, p. 33, Mar. 2007.

[23] J. Dekens, "Local Knowledge for Disaster Preparedness: A literature Review,” 2007.

[24] N. Kapucu, “Collaborative emergency management: better community organising, better public preparedness and response.," Disasters, vol. 32, no. 2, pp. 239-62, Jun. 2008.

[25] A. Chacowry, L. J. McEwen, and K. Lynch, "Recovery and resilience of communities in flood risk zones in a small island developing state: A case study from a suburban settlement of Port Louis, Mauritius,” Int. J. Disaster Risk Reduct., vol. 28, pp. 826-838, Jun. 2018.

[26] J. Fox and J. J. Moreland, “The dark side of social networking sites: An exploration of the relational and psychological stressors associated with Facebook use and affordances," Comput. Human Behav., vol. 45, pp. 168-176, Apr. 2015.

[27] B. Semaan and J. Hemsley, "Maintaining and Creating Social Infrastructures: Towards a Theory of Resilience.”

[28] F. Schultz, S. Utz, and A. G?ritz, "Is the medium the message? Perceptions of and reactions to crisis communication via twitter, blogs and traditional media,” Public Relat. Rev., vol. 37, no. 1, pp. 20-27, Mar. 2011.

[29] S. Utz, F. Schultz, and S. Glocka, “Crisis communication online: How medium, crisis type and emotions affected public reactions in the Fukushima Daiichi nuclear disaster,” Public Relat. Rev., vol. 39, no. 1, pp. 40-46, Mar. 2013.

[30] K. J. Tierney, M. K. Lindell, and R. W. Perry, Facing the unexpected: disaster preparedness and response in the United States. Joseph Henry Press, 2001.

[31] Y. O. Izadkhah and M. Hosseini, “Towards resilient communities in developing countries through education of children for disaster preparedness," Int. J. Emerg. Manag., vol. 2, no. 3, p. 138, 2005.

[32] N. Bharosa, J. Lee, and M. Janssen, "Challenges and obstacles in sharing and coordinating information during multi-agency disaster response: Propositions from field exercises,” Inf. Syst. Front., vol. 12, no. 1, pp. 49-65, Mar. 2010. 
[33] S. R. Hiltz and L. Plotnick, "Dealing with Information Overload When Using Social Media for Emergency Management: Emerging Solutions,” 2013.

[34] R. Rao, L. Plotnick, and S. R. Hiltz, "Supporting the Use of Social Media by Emergency Managers:

Software Tools to Overcome Information Overload," 2017.

[35] N. Kapucu, "Interagency Communication Networks During Emergencies,” Am. Rev. Public Adm., vol. 36, no. 2, pp. 207-225, Jun. 2006.

[36] F. M. Burkle, "Population-based Triage Management in Response to Surge-capacity Requirements during a Large-scale Bioevent Disaster,” Acad. Emerg. Med., vol. 13, no. 11, pp. 1118-1129, Nov. 2006.

[37] M. L. Vanderford, T. Nastoff, J. L. Telfer, and S. E. Bonzo, "Emergency Communication Challenges in Response to Hurricane Katrina: Lessons from the
Centers for Disease Control and Prevention,” J. Appl. Commun. Res., vol. 35, no. 1, pp. 9-25, Feb. 2007.

[38] B. Gray, M. J. Weal, and D. Martin, "Social Media during a Sustained Period of Crisis: The Case of the UK Storms,” no. May, pp. 633-644, 2017.

[39] K. Meesters, L. van Beek, and B. Van de Walle, "\#Help. The Reality of Social Media Use in Crisis Response: Lessons from a Realistic Crisis Exercise,” in 2016 49th Hawaii International Conference on System Sciences (HICSS), 2016, pp. 116-125.

[40] A. Donahue and R. Tuohy, "Lessons We Don’t Learn: A Study of the Lessons of Disasters, Why We Repeat Them, and How We Can Learn Them," Homel. Secur. Aff., vol. 2, no. 2, 2006.

[41] Y. Rogers, "New theoretical approaches for humancomputer interaction,” Annu. Rev. Inf. Sci. Technol., vol. 38, no. 1, pp. 87-143, Sep. 2005. 